\title{
SOX2 Is a Potential Novel Marker of Undifferentiated Thyroid Carcinomas
}

\author{
Wafaey Gomaa ${ }^{1}$, Azmi Marouf ${ }^{2}$, Asayil Alamoudi ${ }^{3}$, Jaudah Al-Maghrabi ${ }^{4}$ \\ 1. Pathology, Minia University, El-Minia, EGY 2. Medicine, King Abdulaziz University, Jeddah, SAU 3. Dentistry, King \\ Abdulaziz University, Jeddah, SAU 4. Pathology, King Abdulaziz University, Jeddah, SAU
}

Corresponding author: Wafaey Gomaa, wafgom@yahoo.com

\section{Abstract \\ Background}

Thyroid cancer is a very common endocrine malignancy. Cancer stem cells are attributable to initiation, progression, and treatment failure in thyroid carcinoma. In the current study, immunostaining of SRY-box 2 (SOX2) in thyroid carcinoma is investigated.

\section{Material and methods}

Tissue microarrays were generated from 219 thyroid carcinomas distributed as follows: papillary thyroid carcinoma (175), follicular thyroid carcinoma (11), medullary thyroid carcinoma (11), Hurthle cell carcinoma (three), poorly differentiated thyroid carcinoma (PTDC; nine), and anaplastic thyroid carcinoma (ATC; 10). Immunohistochemistry for SOX2 was done and examined for nuclear staining. The results were analysed.

\section{Results}

SOX2 immunostaining was positive in one PDTC (out of nine; 11.1\%) and in three ATC (out of 10; 30\%). The rest of the thyroid cancers showed no immunostaining for SOX2.

\section{Conclusion}

The study represents for the first time SOX2 immunostaining on a large number of thyroid carcinomas. We discovered that SOX2 immunostaining is found in PDTC and ATC while SOX2 immunostaining is lacking in other thyroid cancer. SOX2 may be a marker of loss of differentiation in thyroid carcinoma. In vitro as well as in vivo molecular studies are required to explore the possible role of SOX2 in thyroid carcinoma.

Categories: Pathology, Oncology

Keywords: thyroid, carcinoma, tma, sox2, immunohistochemistry

Review began $12 / 08 / 2020$ Review ended 12/15/2020 Published 12/15/2020

(c) Copyright 2020 Gomaa et al. This is an open access article distributed under the terms of the Creative Commons Attribution License CC-BY 4.0., which permits unrestricted use, distribution, and reproduction in any medium, provided the original author and source are credited.

\section{Introduction}

Thyroid cancer is the most common malignancy of endocrine organs. Its incidence continues to rise worldwide [1,2]. Thyroid cancer is one of the most prevalent cancers in Saudi Arabia. In 2014, it was the second most common female cancer in incidence (11.5\% of all cancers) and represented $4.2 \%$ of all cancers in males for that year [3]. The major subtypes of thyroid cancer include papillary thyroid carcinoma (PTC), follicular thyroid carcinoma (FTC), medullary thyroid carcinoma (MTC), poorly differentiated thyroid carcinoma (PDTC), and anaplastic thyroid carcinoma (ATC) [4]. Resistance to chemotherapy is problematic in treatment of thyroid carcinoma. This resistance is related to failure of current medications to target cancer stem cells (CSCs) [5,6].

SRY-box 2 (SOX2) is a transcription factor that is important for tissue regeneration [7] and is well recognised to have critical roles in human and other mammalian embryogenesis [8]. In cancer cells, SOX2 is involved in regulation of cellular proliferation, signalling in apoptosis, invasion, and migration [9]. SOX2 has been detected in different cancer types [10]. A lower SOX2 expression in CSCs promotes greater cell death and response to cisplatin and doxorubicin [11]. SOX2 is expressed in thyroid CSCs [12] and may be an important marker in thyroid CSCs [11].

In the current study, the aim is to investigate the incidence of immunostaining status of SOX2 in thyroid carcinomas and to find the possible relation to clinicopathological features of tumours.

\section{Materials And Methods}

\section{Patients}

The study involved paraffin wax tumour blocks from 219 patients diagnosed with thyroid cancer. The blocks 


\section{Cureus}

were obtained from the archives of the Department of Pathology at King Abdulaziz University, Jeddah, Saudi Arabia. Some clinicopathological characteristics of patients are listed in Table 1 and Table 2 . The study was performed after obtaining agreement of the ethics committee of Faculty of Medicine, King Abdulaziz University, Saudi Arabia (IRB \#1127-13). The study was done in accordance with the Declaration of Helsinki.

\begin{tabular}{|c|c|c|}
\hline Feature & Category & n (\%) \\
\hline \multirow{2}{*}{ Gender } & Female & $167(76 \%)$ \\
\hline & Male & $52(24 \%)$ \\
\hline \multirow{2}{*}{ Age (Range 13-86) } & $<45$ years & $125(57 \%)$ \\
\hline & $\geq 45$ years & $94(43 \%)$ \\
\hline \multirow{2}{*}{ Extrathyroid Extension } & Absent & $182(83 \%)$ \\
\hline & Present & 37 (17\%) \\
\hline \multirow{2}{*}{ Focality } & Unifocal & 130 (59.4\%) \\
\hline & Multifocal & 89 (40.6\%) \\
\hline \multirow{2}{*}{ Lymphovascular Invasion } & Absent & $178(81.3 \%)$ \\
\hline & Present & $41(18.7 \%)$ \\
\hline \multirow{2}{*}{ Capsular Invasion } & Absent & $176(80.4 \%)$ \\
\hline & Present & $43(19.6 \%)$ \\
\hline \multirow{3}{*}{ Nodal Metastasis } & Absent & $30(13.7 \%)$ \\
\hline & Present & $54(24.7 \%)$ \\
\hline & Not assessed & $135(61.6 \%)$ \\
\hline \multirow{2}{*}{ Surgical Resection Margin } & Free & 159 (72.6\%) \\
\hline & Involved & $60(27.4 \%)$ \\
\hline
\end{tabular}

\section{TABLE 1: Clinicopathological features of tumours}

\begin{tabular}{|l|l|}
\hline \hline & Number (\%) \\
\hline Papillary Thyroid Carcinoma (PTC) & $175(80 \%)$ \\
\hline Follicular Thyroid Carcinoma (FTC) & $11(5 \%)$ \\
\hline Medullary Thyroid Carcinoma (MTC) & $11(5 \%)$ \\
Hurthle Cell Carcinoma (HCC) & $3(1.4 \%)$ \\
Poorly Differentiated Thyroid Carcinoma (PTDC) & $9(4.1 \%)$ \\
Anaplastic Thyroid Carcinoma (ATC) & $10(4.5 \%)$ \\
Total & $219(100 \%)$ \\
\hline
\end{tabular}

\section{TABLE 2: Histological subtyping of thyroid neoplasms included in the study}

\section{Tissue microarray}

Tissue microarrays were designed and generated from thyroid cancers. A tissue microarrayer (the automated TMA Master 1.14 SP3 [3D Histech Ltd., Budapest, Hungary]) was used. Placenta tissue was used for orientation. TMA blocks were cut with a thickness of $4 \mu \mathrm{m}$ and kept on positive-charged slides (Leica Microsystems Plus Slides; Leica GmbH, Wetzlar, Germany). 


\section{Cureus}

\section{Immunohistochemistry}

Sections were prepared for immunostaining by deparaffinisation in xylene and rehydration. Immunostaining was performed on BenchMark XT, Ventana ${ }^{\circledR}$ automated immunostainer (Medical Systems Inc., Tucson, AZ, USA). Pre-treatment was done using CC1 (prediluted cell conditioning solution) for $60 \mathrm{~min}$. Monoclonal rabbit anti-human SOX2 antibody (SP76; Cell Marque Corp., Rocklin, CA, USA). A DAB detection kit was used (Ventana ${ }^{\circledR} \mathrm{I}$-view). The slides were washed as appropriate, counterstained with Mayer's haematoxylin and mounted. Negative control and positive control slides were included. SOX2 nuclear immunostaining was reported as the percentage of positive cells.

\section{Statistical analysis}

Descriptive statistics were performed using Statistical Package for Social Sciences (SPSS) version 16 (IBM Corp., Armonk, NY, USA).

\section{Results}

In the present study, we demonstrated nuclear SOX2 immunostaining in some thyroid carcinomas. Positive nuclear immunostaining was observed only in PDTC and ATC. SOX2 immunostaining in other types of thyroid carcinoma was not detected. Nuclear immunostaining was moderate in intensity and diffuse in distribution. SOX2 immunostaining was observed in one out of nine PDTC (11.1\%), and positive in three ATC out of 10 (30\%). The percentage of SOX2 immunostaining in PDTC was 35\%. The positive PDTC belongs to an elderly male with nodal metastasis, capsular invasion, positive margin, positive vascular invasion, and a tumour size of $5.5 \mathrm{~cm}$. In ATC, the mean percentage of positivity was $40 \%$. SOX2-positive ATC patients were females. SOX2-positive ATCs were associated with nodal metastasis, capsular invasion, extrathyroid extension, vascular invasion, positive margins, and large-sized tumours. In addition, distant metastasis was detected in one SOX2-positive ATC. Figure 1 shows positive nuclear immunostaining in PDTC and ATC.
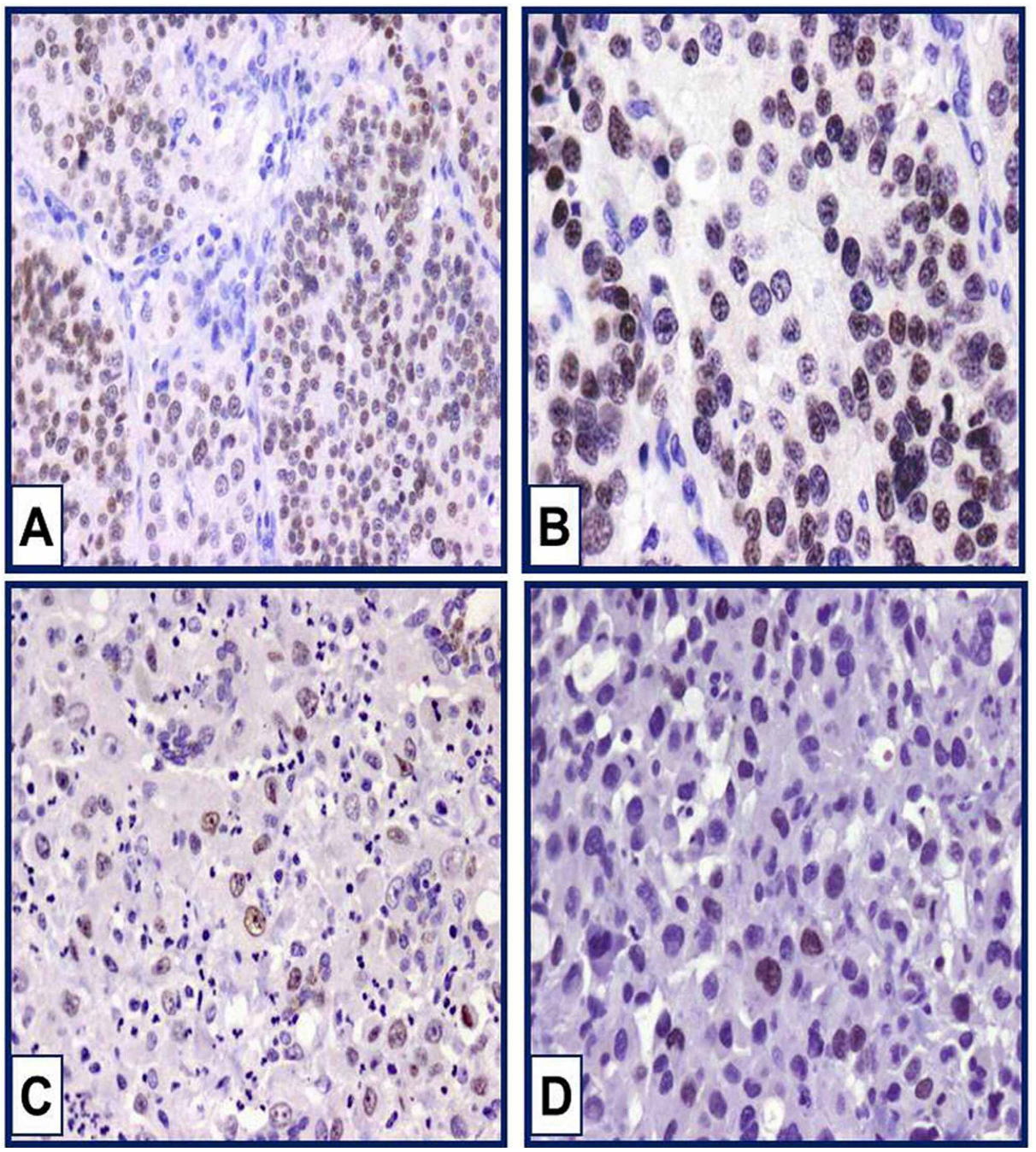

FIGURE 1: SOX2 immunostaining in PDTC and ATC 
Moderate nuclear immunostaining of SOX2 is noticed in poorly differentiated thyroid carcinoma (A). Original magnification was 100x. Weak and moderate nuclear immunostaining of SOX2 in anaplastic thyroid carcinoma (B, C, and D). Original magnification was $200 x$.

PTDC: poorly differentiated thyroid carcinoma; ATC: anaplastic thyroid carcinoma

\section{Discussion}

SOX2 is a transcription factor belonging to the high-mobility SRY-related HMG-box (SOX) family. It plays a vital role in determination of cell fate and maintaining undifferentiated embryonic stem cells, thereby regulating developmental processes $[7,13,14]$.

Abnormal SOX2 expression has been found in different cancers and is correlated with the presence of CSCs [15-17]. In most types of cancers, SOX2 acts as an oncogenic transcriptional factor and is elevated in malignant tissue as compared to normal tissue [8,18-23]. Also, downregulation of SOX2 was found to suppress growth and metastasis of lung cancer [19]. On the other hand, in some studies SOX2 is thought to have a tumour suppressing action based on its reduced expression in some types of cancer, and overexpression inhibited cell proliferation and resulted in cell-cycle arrest and apoptosis [24]. In normal urothelial cells, SOX2 expression was not detected while in pre-neoplastic bladder lesions SOX2 was seen and continued to be expressed in invasive neoplastic lesions [25].

In the current study, we investigate the pattern of SOX2 immunostaining in a large number of thyroid carcinomas for the first time. In thyroid cancer cells, SOX transcription factors were detected in thyroid cancer cell lines [26]. Silencing SOX2 expression in ATC cell lines was associated with a decrease in stemness genes (Nanog and Oct4) expression and increased the sensitivity to chemotherapeutic agent-induced cell death [11].

The current study reported for the first time SOX2 immunostaining on tissue microarrays done from a large number of thyroid carcinomas. In the present study, all PTC were negative for SOX2 immunostaining. This finding is supported on PTC cell lines where SOX2 was reported as a marker of loss of differentiation [27]. In our study, SOX2 immunostaining was detected in $11.1 \%$ of PDTC. In a previous in vitro study, PDTC cell lines showed that SOX2 was not expressed [28]. So far, we reported for the first time immunoexpression of SOX2 in PDTC. Although we have a small number of cases, this finding is worthy to be checked especially when all PTC are negative for SOX2. The second interesting finding in our study is SOX2 positivity in $30 \%$ of cases of ATC. ATC is a rare, highly undifferentiated neoplasm with aggressive and morbid clinical outcome. Surgery is usually palliative, and radiotherapy and chemotherapy are not fully effective. This may be related to inadequate targeting of the cancer-initiating cells [29]. SOX2 appears to play a pivotal role in the resistance of ATC cell lines to chemotherapy through maintaining cell self-renewal by involvement in cell signalling and protein-protein interactions. SOX2 variable positivity in ATC was shown in one study in four out of eight specimens and in an ATC cell line [11]. Our finding is in agreement with this study where the average percentage was around $35 \%$. This is supporting the role of SOX2 in ATC.

We suppose that SOX2 can be used in diagnostic work as a novel marker for undifferentiated thyroid cancers. The limitation of this study is the low number of PDTCs and ATCs and the absence of benign and normal tissues.

\section{Conclusions}

We hereby present for the first time SOX2 immunostaining on the largest cohort of thyroid carcinomas. Interestingly, SOX2 immunostaining was confined to thyroid carcinomas with lack of differentiation (PDTC and ATC). SOX2 is a potential marker of these subtypes of thyroid carcinomas and may help in identifying metastatic ATC and PDTC. These findings, albeit found in a small number of cases, are still interesting and need more confirmation on a larger number of ATC and PDTC. In addition, the prognostic implication of SOX2 immunostaining in these tumours need to be addressed.

\section{Additional Information}

\section{Disclosures}

Human subjects: Consent was obtained by all participants in this study. The ethics committee of Faculty of Medicine, King Abdulaziz University, Saudi Arabia. issued approval 1127-13. The study was performed after obtaining agreement of the ethics committee of Faculty of Medicine, King Abdulaziz University, Saudi Arabia. The study was done in accordance of Declaration of Helsinki. . Animal subjects: All authors have confirmed that this study did not involve animal subjects or tissue. Conflicts of interest: In compliance with the ICMJE uniform disclosure form, all authors declare the following: Payment/services info: All authors have declared that no financial support was received from any organization for the submitted work. Financial relationships: All authors have declared that they have no financial relationships at present or within the previous three years with any organizations that might have an interest in the submitted work. 
Other relationships: All authors have declared that there are no other relationships or activities that could appear to have influenced the submitted work.

\section{References}

1. Siegel R, Naishadham D, Jemal A: Cancer statistics, 2013. CA Cancer J Clin. 2013, 2013:11-30. 10.3322/caac. 21166

2. Sherman SI: Thyroid carcinoma. Lancet. 2003, 501:11. 10.1016/s0140-6736(03)12488-9

3. Cancer incidence report Saudi Arabia 2014. (2014). https://nhic.gov.sa/eServices/Documents/2014.pdf? utm_medium=email\&utm_source=transaction.

4. Kumar V, Abbas A, Aster J: Robbins Basic Pathology. Elsevier, Philadelphia; 2013. https://www.elsevier.com/books/robbins-basic-pathology/kumar/978-0-323-35317-5? utm_medium=email\&utm_source=transaction.

5. Lan L, Luo Y, Cui D, et al.: Epithelial-mesenchymal transition triggers cancer stem cell generation in human thyroid cancer cells. Int J Oncol. 2013, 113-20. 10.3892/ijo.2013.1913

6. Jordan CT, Guzman ML, Noble M: Cancer stem cells. N Engl J Med. 2006, 1253:61. 10.1056/NEJMra061808

7. Sarkar A, Hochedlinger K: The sox family of transcription factors: versatile regulators of stem and progenitor cell fate. Cell Stem Cell. 2013, 15-30. 10.1016/j.stem.2012.12.007

8. Wuebben EL, Rizzino A: The dark side of SOX2: cancer - a comprehensive overview . Oncotarget. 2017, 44917-43. 10.18632/oncotarget.16570

9. Chen Y, Shi L, Zhang L, et al.: The molecular mechanism governing the oncogenic potential of SOX2 in breast cancer. J Biol Chem. 2008, 283:17969-78. 10.1074/jbc.M802917200

10. Vella V, Nicolosi ML, Cantafio P, et al.: DDR1 regulates thyroid cancer cell differentiation via IGF-2/IR-A autocrine signaling loop. Endocr Relat Cancer. 2018, 26:197-214. 10.1530/ERC-18-0310

11. Carina V, Zito G, Pizzolanti G, et al.: Multiple pluripotent stem cell markers in human anaplastic thyroid cancer: the putative upstream role of SOX2. Thyroid. 2013, 23:829-37. 10.1089/thy.2012.0372

12. Lin RY: Thyroid cancer stem cells. Nat Rev Endocrinol. 2011, 7:609-16. 10.1038/nrendo.2011.127

13. Liu K, Lin B, Zhao M, et al.: The multiple roles for Sox2 in stem cell maintenance and tumorigenesis . Cell Signal. 2013, 25:1264-71. 10.1016/j.cellsig.2013.02.013

14. Masui S, Nakatake Y, Toyooka Y, et al.: Pluripotency governed by Sox2 via regulation of Oct3/4 expression in mouse embryonic stem cells. Nat Cell Biol. 2007, 9:625-35. 10.1038/ncb1589

15. Ferone G, Song JY, Sutherland KD, et al.: SOX2 is the determining oncogenic switch in promoting lung squamous cell carcinoma from different cells of origin. Cancer Cell. 2016, 30:519-32. 10.1016/j.ccell.2016.09.001

16. Leis O, Eguiara A, Lopez-Arribillaga E, et al.: Sox2 expression in breast tumours and activation in breast cancer stem cells. Oncogene. 2012, 31:1354-65.

17. Lundberg IV, Edin S, Eklof V, et al.: SOX2 expression is associated with a cancer stem cell state and downregulation of CDX2 in colorectal cancer. BMC Cancer. 2016, 16:471.

18. Santini R, Pietrobono S, Pandolfi S, et al.: SOX2 regulates self-renewal and tumorigenicity of human melanoma-initiating cells. Oncogene. 2014, 33:4697-708. 10.1038/onc.2014.71

19. Xiang R, Liao D, Cheng T, et al.: Downregulation of transcription factor SOX2 in cancer stem cells suppresses growth and metastasis of lung cancer. Br J Cancer. 2011, 104:1410-7. 10.1038/bjc.2011.94

20. Boumahdi S, Driessens G, Lapouge G, et al.: SOX2 controls tumour initiation and cancer stem-cell functions in squamous-cell carcinoma. Nature. 2014, 511:246-50. 10.1038/nature13305

21. Lin F, Lin P, Zhao D, et al.: Sox2 targets cyclinE, $\mathrm{p} 27$ and survivin to regulate androgen-independent human prostate cancer cell proliferation and apoptosis. Cell Prolif. 2012, 45:207-16. 10.1111/j.13652184.2012.00812.x

22. Vanner RJ, Remke M, Gallo M, et al.: Quiescent sox2(+) cells drive hierarchical growth and relapse in sonic hedgehog subgroup medulloblastoma. Cancer Cell. 2014, 26:33-47. 10.1016/j.ccr.2014.05.005

23. Alonso MM, Diez-Valle R, Manterola L, et al.: Genetic and epigenetic modifications of Sox2 contribute to the invasive phenotype of malignant gliomas. PLoS One. 2011, 6:e26740. 10.1371/journal.pone.0026740

24. Otsubo T, Akiyama Y, Yanagihara K, Yuasa Y: SOX2 is frequently downregulated in gastric cancers and inhibits cell growth through cell-cycle arrest and apoptosis. Br J Cancer. 2008, 98:824-31. 10.1038/sj.bjc.6604193

25. Zhu F, Qian W, Zhang H, et al.: SOX2 is a marker for stem-like tumor cells in bladder cancer . Stem Cell Reports. 2017, 9:429-37. 10.1016/j.stemcr.2017.07.004

26. Bauer J, Kopp S, Schlagberger EM, et al.: Proteome analysis of human follicular thyroid cancer cells exposed to the random positioning machine. Int J Mol Sci. 2017, 18:546. 10.3390/ijms18030546

27. Fuziwara CS, Saito KC, Leoni SG, Waitzberg AF, Kimura ET: The highly expressed FAM83F protein in papillary thyroid cancer exerts a pro-oncogenic role in thyroid follicular cells. Front Endocrinol (Lausanne). 2019, 10:134. 10.3389/fendo.2019.00134

28. Warnke E, Pietsch J, Wehland M, et al.: Spheroid formation of human thyroid cancer cells under simulated microgravity: a possible role of CTGF and CAV1. Cell Commun Signal. 2014, 12:32-10.

29. Gharib H, Papini E, Paschke R: Thyroid nodules: a review of current guidelines, practices, and prospects . Eur J Endocrinol. 2008, 159:493-505. 